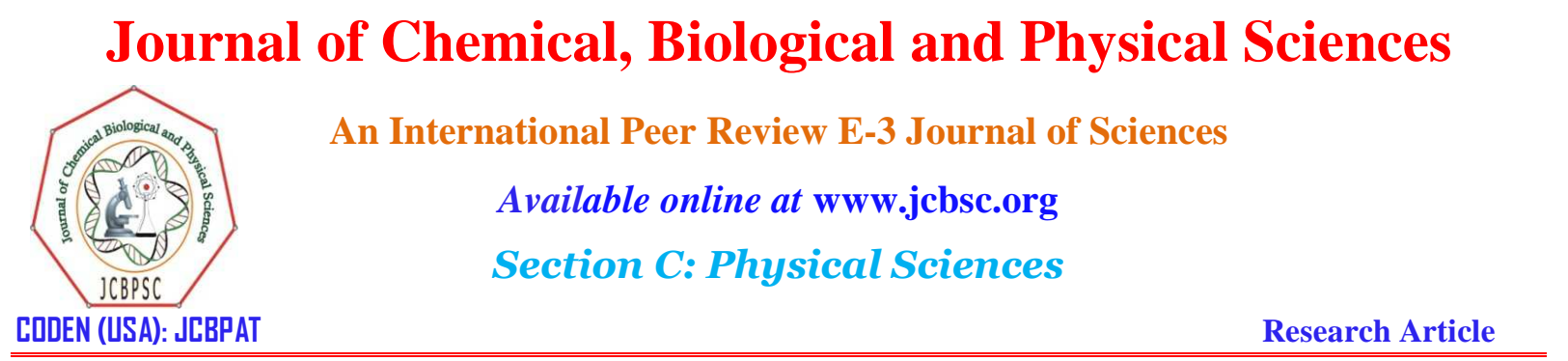

\title{
Unsteady MHD slip flow past a vertical porous plate with radiation and soret effect in a rotating system with fluctuating temperature and concentration in presence of hall current and temperature gradient dependent heat source
}

\author{
K.Balamurugan ${ }^{1}$ and V.Gopikrishnan ${ }^{2}$ \\ ${ }^{1}$ Department of Mathematics, Government Arts College, Tiruvannamalai, India. \\ ${ }^{2}$ Department of Mathematics, Shanmuga Industries Arts and Science College, Tiruvannamalai, India.
}

Received: 07 August 2017; Revised: 23 August 2017; Accepted: 30 August 2017

\begin{abstract}
This paper analyze unsteady free convection heat and mass transfer flow through a non-homogeneous porous medium bounded by an infinite porous vertical plate with slip flow taking into account the radiation, chemical reaction, hall current, soret effect and temperature gradient dependent heat source. The approximate profiles for velocity, temperature, concentration are obtained by using perturbation techniques. The expressions for skin friction, heat and mass flux are derived.
\end{abstract}

Keywords: MHD, radiation, rotation parameter, soret effect, Hall Effect, chemical reaction, temperature gradient dependent heat source, fluctuating temperature and concentration. 


\section{INTRODUCTION}

Natural convection flow induced by buoyancy forces acting over bodies with different geometries in a fluid along a porous medium is prevalent in many natural phenomena and has varied and wide range of industrial applications, for example in atmospheric flows, the presence of pure air or water is not possible because of some foreign mass may be present naturally or artificially due to industrial emissions. Free convection arises in fluids when temperature changes cause density variation leading to buoyancy forces acting on the fluid elements. Natural processes such as vaporization of mist and fog, photosynthesis are occur due to thermal and buoyancy forces developed as a result of difference in temperature or concentration or a combination of these two. Such configuration plays vital role in industry based applications like heat exchange devices, cooling of molten metals, insulation systems, filtration, chemical catalytic reactors and processes.

In many practical applications, the particle adjacent to a solid surface no longer takes the velocity of the surface. The particles at the surface has a finite tangential velocities, it slips along the surface. Such a flow regime is called the slip-flow regime and this effect cannot be neglected. At the macroscopic level, it is accepted that the boundary condition for a viscous fluid at a solid wall is the so called no-slip one. While has been proven experimentally to be accurate for a number of macroscopic flows, it remains an assumption that is based on physical principles. In fact nearly two hundred years ago, Navier's proposes a general boundary condition that incorporates the possibility of fluid slip at a solid boundary. Navier's proposed condition assumes that the fluid slip-velocity at a solid surface is proportional to the shear stress at the surface. Agarwal HL et al. ${ }^{l}$ have studied that effects of Hall currents on the hydro-magnetic free convection with mass transfer in a rotating fluid. Akindele Michael Okedoye ${ }^{2}$ has studied that Analytical solution of MHD free convective heat and mass transfer flow in a porous medium.

Balamurugan K. et al. ${ }^{3}$ have investigated the Chemical reaction effects on Heat and Mass Transfer of Unsteady flow over an infinite vertical porous plate embedded in a porous medium with heat source. Balamurugan K.S. et al. ${ }^{4}$ have studied the thermo diffusion and chemical reaction effects on a three dimensional MHD mixed convective flow along an infinite vertical porous plate with viscous and Joules dissipation. Jaiswal B.S and Soundalgekar V.M. ${ }^{5}$ have studied the oscillating plate temperature effects on a flow past an infinite porous plate with constant suction and embedded in a porous medium. Jha B.K, et $a l^{6}$ have studied mass transfer effects on the flow past an exponentially accelerated vertical plate with constant heat flux. Kim Y.J. ${ }^{7}$ has investigated the unsteady MHD Convective heat transfer past a semiinfinite vertical porous moving plate with variable suction.

Kumar $\mathrm{H}^{8}$ has studied the radiative heat transfer with hydro magnetic flow and viscous dissipation over stretching surface in the presence of variable heat flux. Lighthill M.J. ${ }^{9}$ has investigated the response of laminar skin friction and heat transfer to fluctuation in the stream velocity. Makinde O.D. et al. ${ }^{10}$.have studied the unsteady free convection flow with suction on an accelerating porous plate. Maygari E. et al. ${ }^{11}$ have studied the analytical solutions for unsteady free convection flow through a Porous medium in the stream velocity. Mbeledogu.U and Ogulu. $\mathrm{A}^{12}$ have investigated that the Heat and mass transfer of an unsteady MHD natural convection flow of a rotating fluid past a vertical porous flat plate in the presence of radiative heat transfer. Muthucumarasamy, $\mathrm{R}^{13}$ has studied the effect of Heat and mass transfer on flow past an oscillatory vertical plate with variable temperature. Raptis A.A. ${ }^{14}$ has investigated the fluid flow through a porous medium in the presence of magnetic field.

867 J. Chem. Bio. Phy. Sci. Sec. C, August 2017 - October, 2017, Vol. 7, No. 4; 866-880. [DDI: 10.24214/jchps.C.7.4.86680.] 
Raptis A.A., Kafousias $\mathrm{N}^{15}$ have investigated the heat Transfer in flow through a porous medium bounded by an infinite vertical plate under the action of a magnetic field. Sarada $\mathrm{K}$ and Shanker B. $^{16}$ have investigated the effects of Soret and Dufour on an unsteady MHD free convection flow past a vertical porous plate in the presence of suction or injection. Singh K.D and Kumar $\mathrm{R}^{17}$ have investiged combine effects of hall current and rotation on free convection MHD flow in a porous channel. Srinivasa Rao G et.al. ${ }^{18}$ have studied Soret and Dufour effects on MHD boundary layer flow over a moving vertical porous plate with suction.

\section{FORMULATION OF THE PROBLEM}

We consider the flow of an electrically conducting viscous incompressible fluid flow along an infinite vertical porous plate. Choose $x^{\prime}$ axis along the plate and $y^{\prime}$ axis normal to it. The flow is oriented vertically upward along the $x^{\prime}$-direction. Hence all the physical properties of the fluid are functions of $y^{\prime}$ and $t^{\prime}$.

Under the usual Boussinesq approximations the flow is governed by the following system of equations.

$$
\frac{\partial v^{\prime}}{\partial y^{\prime}}=0
$$

$\frac{\partial u^{\prime}}{\partial t^{\prime}}+v^{\prime} \frac{\partial u^{\prime}}{\partial y^{\prime}}+2 K w^{\prime}=v \frac{\partial^{2} u^{\prime}}{\partial y^{\prime 2}}-\frac{\sigma B_{0}^{2}}{\rho\left(1+m^{2}\right)}\left(u^{\prime}+m w^{\prime}\right)+g \beta\left(T^{\prime}-T_{\infty}\right)+g \beta_{c}\left(C^{\prime}-C_{\infty}\right)-\frac{v}{K^{\prime} p} u^{\prime}$

$\frac{\partial w^{\prime}}{\partial t^{\prime}}+v^{\prime} \frac{\partial w^{\prime}}{\partial y^{\prime}}-2 K u^{\prime}=v \frac{\partial^{2} w^{\prime}}{\partial y^{\prime 2}}+\frac{\sigma B_{0}^{2}}{\rho\left(1+m^{2}\right)}\left(m u^{\prime}-w^{\prime}\right)-\frac{v}{K^{\prime} p} w^{\prime}$

$\frac{\partial T^{\prime}}{\partial t^{\prime}}+v^{\prime} \frac{\partial T^{\prime}}{\partial y^{\prime}}=\frac{k}{\rho C_{p}} \frac{\partial^{2} T^{\prime}}{\partial y^{\prime 2}}+\frac{Q^{\prime}}{\rho C_{p}} \frac{\partial T}{\partial y}-\frac{1}{\rho C_{p}} \frac{\partial q_{r}^{\prime}}{\partial y^{\prime}}$

$\frac{\partial C^{\prime}}{\partial t^{\prime}}+v^{\prime} \frac{\partial C^{\prime}}{\partial y^{\prime}}=D \frac{\partial^{2} C^{\prime}}{\partial y^{\prime 2}}+\frac{D K_{T}}{T_{M}} \frac{\partial^{2} T^{\prime}}{\partial y^{\prime 2}}-K_{0}^{\prime}\left(C^{\prime}-C_{\infty}^{\prime}\right)$

The boundary conditions are

$$
\begin{array}{ll}
u^{\prime}=L_{1}\left(\frac{\partial u^{\prime}}{\partial y^{\prime}}\right), w^{\prime}=L_{1}\left(\frac{\partial w^{\prime}}{\partial y^{\prime}}\right), T^{\prime}=T_{w}^{\prime}+\varepsilon\left(T_{w}^{\prime}-T_{\infty}^{\prime}\right) e^{i n^{\prime} t^{\prime}} \\
C^{\prime}=C_{w}^{\prime}+\varepsilon\left(C_{w}^{\prime}-C_{\infty}^{\prime}\right) e^{i n^{\prime} t^{\prime}} & \text { at } y^{\prime}=0 \\
u^{\prime} \rightarrow 0, T^{\prime} \rightarrow T_{\infty}^{\prime} C^{\prime} \rightarrow C_{\infty}^{\prime} & \text { at } y^{\prime} \rightarrow \infty
\end{array}
$$

$u^{\prime}, v^{\prime}$ and $w^{\prime}$ are velocity components of velocity along $\mathrm{x}$-axis, $\mathrm{y}$-axis and z-axis directions respectively. $\mathrm{t}$ is the time, $\mathrm{g}$ is the acceleration due to gravity, $\beta$ and $\beta_{c}$ are the coefficients of volume 
expansion, $\boldsymbol{V}$ is the kinematic viscosity, $K_{0}^{\prime}$ is the chemical reaction of the fluid flow, $\rho$ is the density of the fluid, $\sigma$ is the electrical conductivity of the fluid, $B_{0}$ is the uniform magnetic field, $T^{\prime}$ is the temperature, $C_{p}$ is the specific heat at constant pressure, $q_{r}$ is the radioactive heat flux, $T_{w}^{\prime}$ is the temperature of the plate, $T_{\infty}$ is the temperature of the fluid away from the plate, $L=\left(\frac{2-m_{1}}{m_{1}}\right)$ being the mean free path where $m_{1}$ is the Maxwell reflection coefficient, $C^{\prime}$ is the concentration, $C_{w}{ }^{\prime}$ is the concentration of the fluid at the wall as well as $C_{w}$ is the concentration of the fluid away from the plate.

The equation of continuity (7.1) yields that $v^{\prime}$ is either a constant or some function of time, hence we assume that $v^{\prime}=-v_{0}^{\prime}\left(1+\varepsilon e^{-n^{\prime} t^{\prime}}\right)$

$v_{0}$ is the suction velocity at the plate and $n$ is the positive constant. The negative sign indicates that the suction velocity acts towards the plate.

Consider the fluid which is optically thin with a relatively low density and radioactive heat flux is given by $\frac{\partial q_{r}^{\prime}}{\partial y^{\prime}}=4\left(T^{\prime}-T_{\infty}^{\prime}\right) I$, where $\mathrm{I}$ is the absorption coefficient at the plate.

On introducing the following dimensionless quantities

$$
\begin{aligned}
& y=\frac{y^{\prime} v_{0}^{\prime}}{v}, t=\frac{v_{0}^{\prime} t^{\prime}}{4 v}, u=\frac{u^{\prime}}{v_{0}^{\prime}}, w=\frac{w^{\prime}}{v_{0}^{\prime}}, n=\frac{4 v n^{\prime}}{v_{0}^{\prime 2}}, M=\frac{\sigma B_{0}^{2} v}{v_{0}^{\prime 2}}, G r=\frac{g \beta v\left(T_{w}^{\prime}-T_{\infty}^{\prime}\right)}{v_{0}^{\prime 3}} \\
& G m=\frac{g \beta_{c} v\left(C_{w}^{\prime}-C_{\infty}^{\prime}\right)}{v_{0}^{\prime 3}}, K p=\frac{K^{\prime} p v_{0}^{\prime 2}}{v^{2}}, T=\frac{T^{\prime}-T_{\infty}^{\prime}}{T_{w}^{\prime}-T_{\infty}^{\prime}}, C=\frac{C^{\prime}-C_{\infty}^{\prime}}{C_{w}^{\prime}-C_{\infty}^{\prime}}, \operatorname{Pr}=\frac{\mu C_{p}}{k} \\
& K=\frac{K^{\prime} v}{v_{0}^{\prime 2}}, S_{0}=\frac{D K_{T}\left(T_{w}^{\prime}-T_{\infty}^{\prime}\right)}{v T_{M}\left(C_{w}^{\prime}-C_{\infty}^{\prime}\right)}, K o=\frac{K^{\prime} o v}{v_{0}^{\prime 2}}, R=\frac{4 v I}{\rho C_{p} v_{0}^{\prime 2}}, h=\frac{L_{1} v_{0}^{\prime 2}}{v}
\end{aligned}
$$

The equations (2),(3), and (4),(5) becomes

$$
\begin{aligned}
& \frac{1}{4} \frac{\partial u}{\partial t}-\left(1+\varepsilon e^{-n t}\right) \frac{\partial u}{\partial y}+2 K w=\frac{\partial^{2} u}{\partial y^{2}}-\frac{M}{1+m^{2}}(u+m w)+G r T+G m C-\frac{1}{K p} u \\
& \frac{1}{4} \frac{\partial w}{\partial t}-\left(1+\varepsilon e^{-n t}\right) \frac{\partial w}{\partial y}-2 K u=\frac{\partial^{2} w}{\partial y^{2}}+\frac{M}{1+m^{2}}(m u-w)-\frac{1}{K p} w \\
& \frac{1}{4} \frac{\partial T}{\partial t}-\left(1+\varepsilon e^{-n t}\right) \frac{\partial T}{\partial y}=\frac{1}{\operatorname{Pr}} \frac{\partial^{2} T}{\partial y^{2}}+H \frac{\partial T}{\partial y}-R T \\
& \frac{1}{4} \frac{\partial C}{\partial t}-\left(1+\varepsilon e^{-n t}\right) \frac{\partial C}{\partial y}=\frac{1}{S c} \frac{\partial^{2} C}{\partial y^{2}}+S o \frac{\partial^{2} T}{\partial y^{2}}-K o C
\end{aligned}
$$


The corresponding boundary conditions becomes

$$
\begin{aligned}
& u=h \frac{\partial u}{\partial y}, w=h \frac{\partial w}{\partial y}, T=1+\varepsilon e^{\mathrm{int}}, C=1+\varepsilon e^{\mathrm{int}}, \quad \text { at } y=0 \\
& u \rightarrow 0, T \rightarrow 0, C \rightarrow 0, \quad \text { as } y \rightarrow \infty
\end{aligned}
$$

Where,

$G r=\frac{\nu g \beta\left(T_{w}^{\prime}-T_{\infty}^{\prime}\right)}{v_{0}^{\prime 3}}$ is the Grashof number, $G m=\frac{\nu g \beta_{c}\left(C_{w}^{\prime}-C_{\infty}^{\prime}\right)}{v_{0}^{\prime 3}}$ is the modified Grashof number $M=\frac{\sigma B_{0}^{2} v}{v_{0}^{2}} \quad$ is the magnetic number, $K p=\frac{K p^{\prime} v_{0}^{2}}{v^{2}} \quad$ is the Permeability

$K o=\frac{K^{\prime} O V}{v_{0}^{\prime 2}}$ is the chemical reaction parameter, $S o=\frac{D K_{T}\left(T_{w}^{\prime}-T_{\infty}^{\prime}\right)}{V T_{m}\left(C_{w}^{\prime}-C_{\infty}^{\prime}\right)} \quad$ is the soret number,

$K=\frac{v K^{\prime}}{v_{0}^{\prime 2}}$ is the rotation parameter, $R=\frac{4 v I}{\rho C_{p} v_{0}^{\prime 2}}$ is the Radiation Parameter,

$\operatorname{Pr}=\frac{\mu C_{p}}{k}$ is the Prandtl number

The equations (10) and (11) can be combined into a single equation by taking $F=u+i w$, we get the following differential equation.

$$
\frac{1}{4} \frac{\partial \mathrm{F}}{\partial \mathrm{t}}-\left(1+\varepsilon \mathrm{e}^{-\mathrm{nt}}\right) \frac{\partial \mathrm{F}}{\partial \mathrm{y}}=\frac{\partial^{2} \mathrm{~F}}{\partial \mathrm{y}^{2}}-\left(\mathrm{M}_{1}+\frac{1}{\mathrm{Kp}}-2 \mathrm{iK}\right) \mathrm{F}+\mathrm{GrT}+\mathrm{GmC}
$$

Where, $M_{1}=\frac{M}{1+m^{2}}(1-i m)$

With boundary conditions,

$$
F=h\left(\frac{\partial F}{\partial y}\right) \text {, on } y=0 \quad F \rightarrow 0 \text {, as } y \rightarrow \infty
$$




\section{METHOD OF SOLUTION}

To solve equations (12), (13) and (15), Assuming $\varepsilon$ to be small so that one can express $F, T$ and $C$ as a regular perturbation series interms of $\varepsilon$ in the neighborhood of the plate as

$$
\left.\begin{array}{l}
F(y, t)=F_{0}(y)+\varepsilon F_{1}(y) e^{-n t} \\
T(y, t)=T_{0}(y)+\varepsilon T_{1}(y) e^{-n t} \\
C(y, t)=C_{0}(y)+\varepsilon C_{1}(y) e^{-n t}
\end{array}\right\}
$$

Using (17) in the equations (12), (13) \& (15) and equating the coefficient of $\varepsilon^{0}, \varepsilon^{1}$ neglecting $\varepsilon^{2}$ terms etc., then we get the set of ordinary differential equations

$$
\begin{aligned}
& F_{0}^{\prime \prime}+F_{0}^{\prime}-\left(M_{1}+\frac{1}{K p}-2 i K\right) F_{0}=-G r T_{0}-G m C_{0} \\
& F_{1}^{\prime \prime}+F_{1}^{\prime}-\left(M_{1}+\frac{1}{K p}-2 i K-\frac{n}{4}\right) F_{1}=-F_{0}^{\prime}-G r T_{1}-G m C_{1} \\
& T_{0}^{\prime \prime}+\operatorname{Pr} T_{0}^{\prime}+-R \operatorname{Pr} T_{0}=0 \\
& T_{1}^{\prime \prime}+\operatorname{Pr} T_{1}^{\prime}+-\left(R-\frac{n}{4}\right) \operatorname{Pr} T_{1}=-\operatorname{Pr} T_{0}^{\prime} \\
& C_{0}^{\prime \prime}+S c C_{0}^{\prime}-S c K_{0} C_{0}=-S c S_{0} T_{0}^{\prime \prime} \\
& \mathrm{C}_{1}^{\prime \prime}+\mathrm{ScC}_{1}^{\prime}-\left(\mathrm{K}_{0}-\frac{\mathrm{n}}{4}\right) \mathrm{ScC}_{1}=-\mathrm{ScC}_{0}^{\prime}-\mathrm{ScS}_{0} \mathrm{~T}_{1}^{\prime \prime}
\end{aligned}
$$

On solving the above differential equations with following boundary conditions, we get the set of solutions as below

$$
\begin{array}{ll}
F_{0}=h\left(\frac{\partial F_{0}}{\partial y}\right), \mathrm{F}_{1}=h\left(\frac{\partial F_{1}}{\partial y}\right), T_{0}=1, T_{1}=1, C_{0}=1, C_{1}=1, & y=0 \\
F_{0}=0, F_{1}=0, T_{0}=0, T_{1}=0, C_{0}=0, C_{1}=0, & y \rightarrow \infty \\
\mathrm{T}_{0}=\mathrm{e}^{\mathrm{m}_{1} \mathrm{y}} & \\
\mathrm{T}_{1}=\mathrm{A}_{1} \mathrm{e}^{\mathrm{m}_{2} \mathrm{y}}+\mathrm{A}_{2} \mathrm{e}^{\mathrm{m}_{1} \mathrm{y}} & \\
\mathrm{T}=\mathrm{e}^{\mathrm{m}_{1} \mathrm{y}}+\varepsilon\left(\mathrm{A}_{1} \mathrm{e}^{\mathrm{m}_{2} \mathrm{y}}+\mathrm{A}_{2} \mathrm{e}^{\mathrm{m}_{1} \mathrm{y}}\right) \mathrm{e}^{-\mathrm{nt}}
\end{array}
$$




$$
\begin{aligned}
& \mathrm{C}_{0}=\mathrm{A}_{3} \mathrm{e}^{\mathrm{m}_{3} \mathrm{y}}+\mathrm{A}_{4} \mathrm{e}^{\mathrm{m}_{1} \mathrm{y}} \\
& \mathrm{C}_{1}=\mathrm{A}_{9} \mathrm{e}^{\mathrm{m}_{4} \mathrm{y}}+\mathrm{A}_{10} \mathrm{e}^{\mathrm{m}_{3} \mathrm{y}}+\mathrm{A}_{11} \mathrm{e}^{\mathrm{m}_{1} \mathrm{y}}+\mathrm{A}_{12} \mathrm{e}^{\mathrm{m}_{2} \mathrm{y}}+\mathrm{A}_{13} \mathrm{e}^{\mathrm{m}_{1} \mathrm{y}} \\
& \mathrm{C}=\mathrm{A}_{3} \mathrm{e}^{\mathrm{m}_{3} \mathrm{y}}+\mathrm{A}_{4} \mathrm{e}^{\mathrm{m}_{1} \mathrm{y}}+\varepsilon\left(\mathrm{A}_{9} \mathrm{e}^{\mathrm{m}_{4} \mathrm{y}}+\mathrm{A}_{10} \mathrm{e}^{\mathrm{m}_{3} \mathrm{y}}+\mathrm{A}_{11} \mathrm{e}^{\mathrm{m}_{1} \mathrm{y}}+\mathrm{A}_{12} \mathrm{e}^{\mathrm{m}_{2} \mathrm{y}}+\mathrm{A}_{13} \mathrm{e}^{\mathrm{m}_{1} \mathrm{y}}\right) \mathrm{e}^{-\mathrm{nt}} \\
& \mathrm{F}_{0}=\mathrm{A}_{5} \mathrm{e}^{\mathrm{m}_{5} \mathrm{y}}+\mathrm{A}_{6} \mathrm{e}^{\mathrm{m}_{1} \mathrm{y}}+\mathrm{A}_{7} \mathrm{e}^{\mathrm{m}_{3} \mathrm{y}}+\mathrm{A}_{8} \mathrm{e}^{\mathrm{m}_{1} \mathrm{y}} \\
& \mathrm{F}_{1}=\mathrm{A}_{14} \mathrm{e}^{\mathrm{m}_{6} \mathrm{y}}+\mathrm{A}_{15} \mathrm{e}^{\mathrm{m}_{4} \mathrm{y}}+\mathrm{A}_{16} \mathrm{e}^{\mathrm{m}_{1} \mathrm{y}}+\mathrm{A}_{17} \mathrm{e}^{\mathrm{m}_{3} \mathrm{y}}+\mathrm{A}_{18} \mathrm{e}^{\mathrm{m}_{1} \mathrm{y}}+\mathrm{A}_{19} \mathrm{e}^{\mathrm{m}_{22} y}+\mathrm{A}_{20} \mathrm{e}^{\mathrm{m}_{1} \mathrm{y}}+\mathrm{A}_{21} \mathrm{e}^{\mathrm{m}_{4} \mathrm{y}} \\
& +\mathrm{A}_{22} \mathrm{e}^{\mathrm{m}_{3} \mathrm{y}}+\mathrm{A}_{23} \mathrm{e}^{\mathrm{m}_{1} \mathrm{y}}+\mathrm{A}_{24} \mathrm{e}^{\mathrm{m}_{2} \mathrm{y}}+\mathrm{A}_{25} \mathrm{e}^{\mathrm{m}_{1} \mathrm{y}}
\end{aligned}
$$

$\mathrm{A}_{1}, \mathrm{~A}_{2}, \mathrm{~A}_{3}, \mathrm{~A}_{4}, \mathrm{~A}_{5}, \mathrm{~A}_{6}, \mathrm{~A}_{7}, \mathrm{~A}_{8}, \mathrm{~A}_{9}, \mathrm{~A}_{10}, \mathrm{~A}_{11}, \mathrm{~A}_{12}, \mathrm{~A}_{13}, \mathrm{~A}_{14}, \mathrm{~A}_{15}, \mathrm{~A}_{16}, \mathrm{~A}_{17}, \mathrm{~m}_{1}, \mathrm{~m}_{2}, \mathrm{~m}_{3}, \mathrm{~m}_{4}, \mathrm{~m}_{5}, \mathrm{~m}_{6}$, $A_{18}, A_{19}, A_{20}, A_{21}, A_{22}, A_{23}, A_{24}, A_{25}$, expression for the constants are given in Appendix.

Skin Friction: The Skin friction for the velocity F is given by

$$
\begin{aligned}
\tau_{\mathrm{w}}=-\mu\left(\frac{\partial \mathrm{F}}{\partial \mathrm{y}}\right)_{\mathrm{y}=0}= & \mathrm{A}_{5} \mathrm{~m}_{5}+\mathrm{A}_{6} \mathrm{~m}_{1}+\mathrm{A}_{7} \mathrm{~m}_{3}+\mathrm{A}_{8} \mathrm{~m}_{1}+\mathcal{E}\left(\mathrm{A}_{14} \mathrm{~m}_{6}+\mathrm{A}_{15} \mathrm{~m}_{4}+\mathrm{A}_{16} \mathrm{~m}_{1}+\mathrm{A}_{17} \mathrm{~m}_{3}+\right. \\
& \left.\mathrm{A}_{18} \mathrm{~m}_{1}+\mathrm{A}_{19} \mathrm{~m}_{2}+\mathrm{A}_{20} \mathrm{~m}_{1}+\mathrm{A}_{21} \mathrm{~m}_{4}+\mathrm{A}_{22} \mathrm{~m}_{3}+\mathrm{A}_{23} \mathrm{~m}_{1}+\mathrm{A}_{24} \mathrm{~m}_{2}+\mathrm{A}_{25} \mathrm{~m}_{1}\right) \mathrm{e}^{-\mathrm{nt}}
\end{aligned}
$$

Heat Flux: The rate of heat transfer at the plate of non-dimensional nusselt number is given by

$$
\mathrm{Nu}=-\left(\frac{\partial \mathrm{T}}{\partial \mathrm{y}}\right)=\mathrm{m}_{1}+\varepsilon\left(\mathrm{A}_{1} \mathrm{~m}_{2}+\mathrm{A}_{2} \mathrm{~m}_{1}\right) \mathrm{e}^{-\mathrm{nt}}
$$

Mass Flux: The rate of mass transfer at the plate of non-dimensional Sherwood Number is given by

$$
\mathrm{Sh}=-\left(\frac{\partial \mathrm{C}}{\partial \mathrm{y}}\right)_{\mathrm{y}=0}=\mathrm{A}_{3} \mathrm{~m}_{3}+\mathrm{A}_{4} \mathrm{~m}_{1}+\varepsilon\left(\mathrm{A}_{9} \mathrm{~m}_{4}+\mathrm{A}_{10} \mathrm{~m}_{3}+\mathrm{A}_{11} \mathrm{~m}_{1}+\mathrm{A}_{12} \mathrm{~m}_{2}+\mathrm{A}_{13} \mathrm{~m}_{1}\right) \mathrm{e}^{-\mathrm{nt}}
$$

\section{RESULTS AND DISCUSSION}

Here, some of the results of physical interest on the velocity, temperature, concentration distribution and also on the wall shear stress and the rate of heat transfer, rate of mass transfer at the wall were discussed. Further, the result is also in good agreement with the result of Madhusudhana Rao et.al, if omit hall current, soret effect and rotating frame of reference.

We have studied the main flow velocity, secondary flow velocity, temperature and concentration by including various parameters like Prandtl Number, Suction parameter, Schmidt number, Thermal Grashof number and mass Grashof number. The effect of flow parameters on velocity field, Temperature field, Concentration field, skin friction, heat flux and mass flux have been analyzed numerically and discussed with the help of numerical values. 
Figures 1, 2 and 3 depict the temperature of the fluid. It is observed that increase of Prandtl, temperature gradient and radiation retards the temperature of the fluid flow. In figures 6, 7 depicts the profile of the concentration of the fluid flow. Here, Increase of Schmidt number and chemical reaction retards the concentration of the fluid flow. Increases of Schmidt number are seemed to decrease the concentration profile of the fluid flow due to the decrease in the molecular diffusivity. But in figure 5 the increases of Soret parameter increase the concentration profile of the fluid. In these sense, involving various parameters to analysis the fluid flow along infinite vertical porous plate .In velocity profile from figure $\mathbf{8}$, increase of Grash of number increases the main velocity of the fluid flow, It implies that thermal buoyancy assisting the velocity of the fluid flow throughout the flow field. In figure 10 depict that increases of rotation parameter retards the primary velocity of the fluid flow because of increases of coriolis force retards the forward flow of the fluid. Figure 9 illustrates velocity distribution increases with an increase of soret number from which we conclude that the fluid velocity rises due to greater thermal diffusion. In figure 11 the increases of hall current retard the primary velocity of the fluid flow. Velocity profiles with the variations of slip parameter $h$, it is observed that the significance of the velocity is high near the plate and there after it decreases and reach to the stationary position at the other end. The increase influence of magnetic parameter on both primary of the fluid goes on decrease due to resistance force which is oppose to the velocity of the fluid flow.

Figures 18 to 20 depict that the skin friction shows the increase effects while increasing of Hall Effect. Heat flux shows the decrease effect if increase of radiation parameter. But mass flux shows increase effects while increase of Soret number.

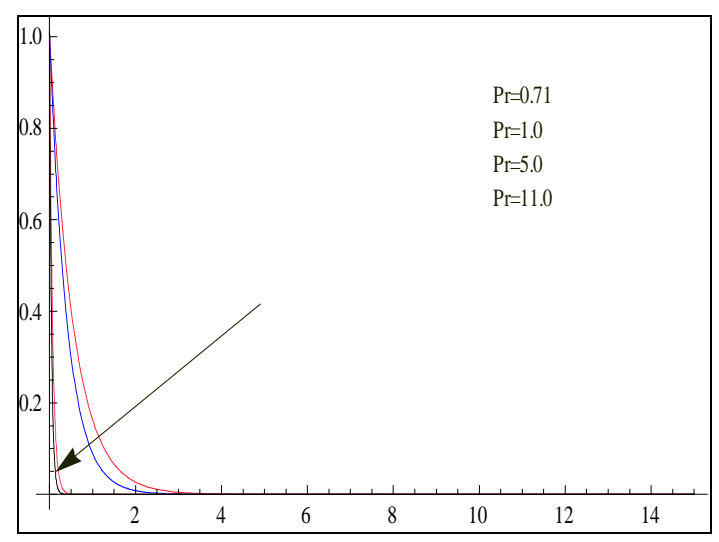

Figure 1: Temperature Profile for various values of pr

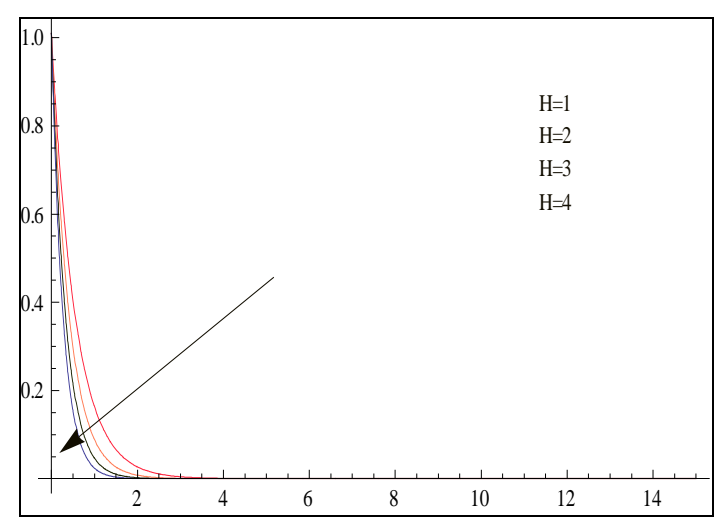

Figure 2: Temperature Profile for various values of $\mathbf{H}$ 




Figure 3: Temperature Profile for various values of $R$

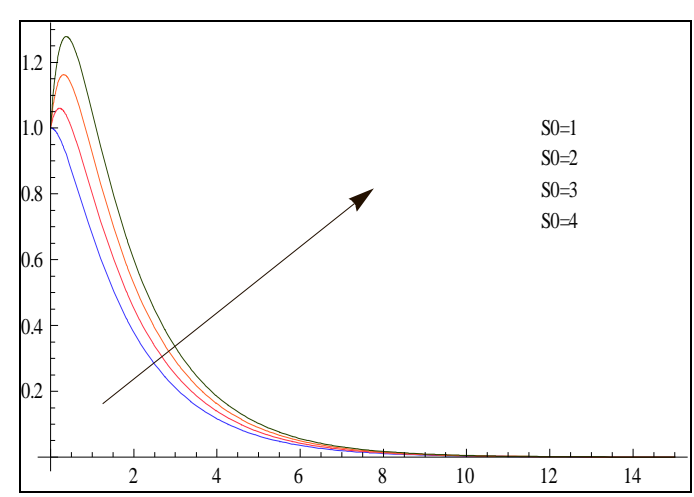

Figure 5: concentration Profile for various values of of $S_{0}$



Figure 7: concentration Profile for various values of $\mathrm{K}_{0}$



Figure 4: concentration Profile for various values of $\mathrm{H}$

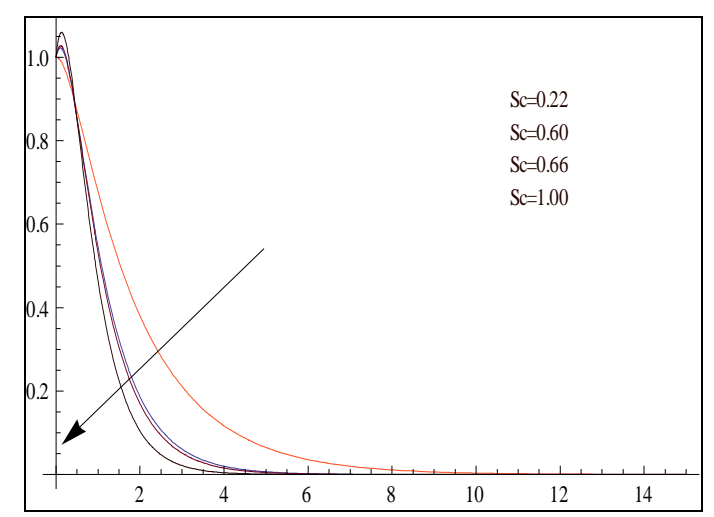

Figure 6: concentration Profile for various values of $\mathrm{Sc}$

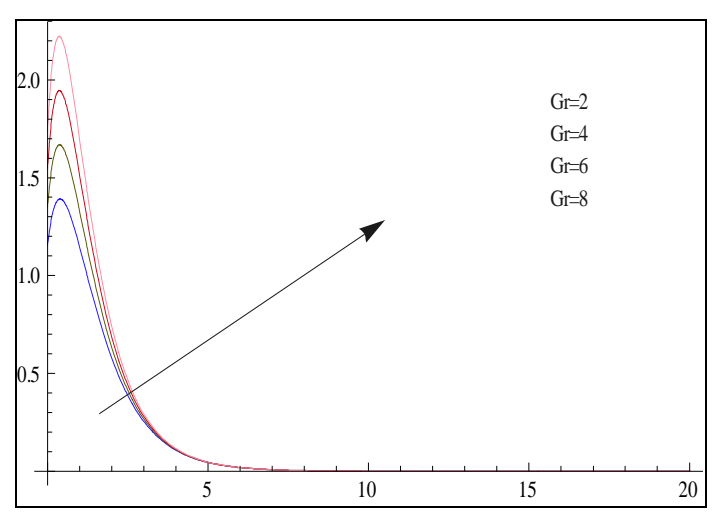

Figure 8: Velocity Profile for various values of $G_{r}$ 


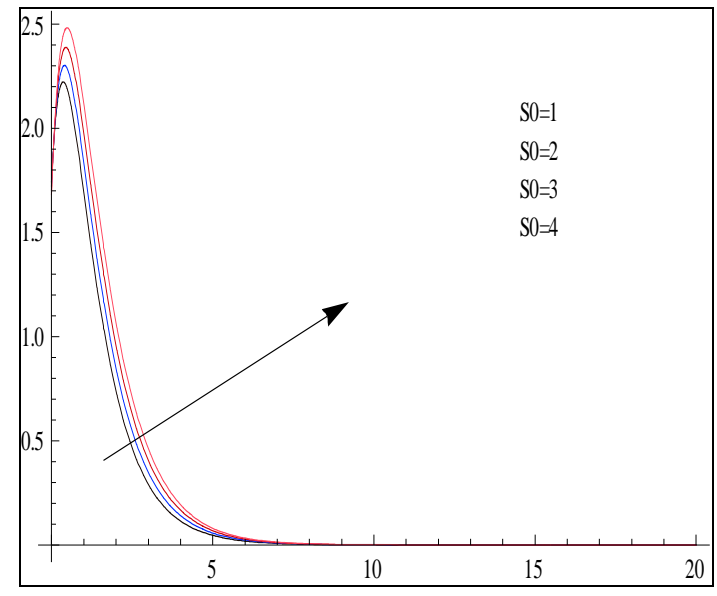

Figure 9: velocity Profile for various values of $S_{0}$

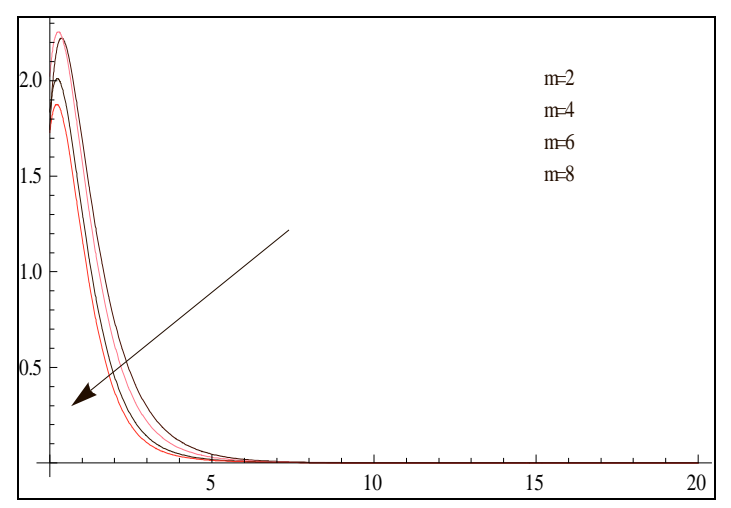

Figure 11: Main Velocity for various values of $m$

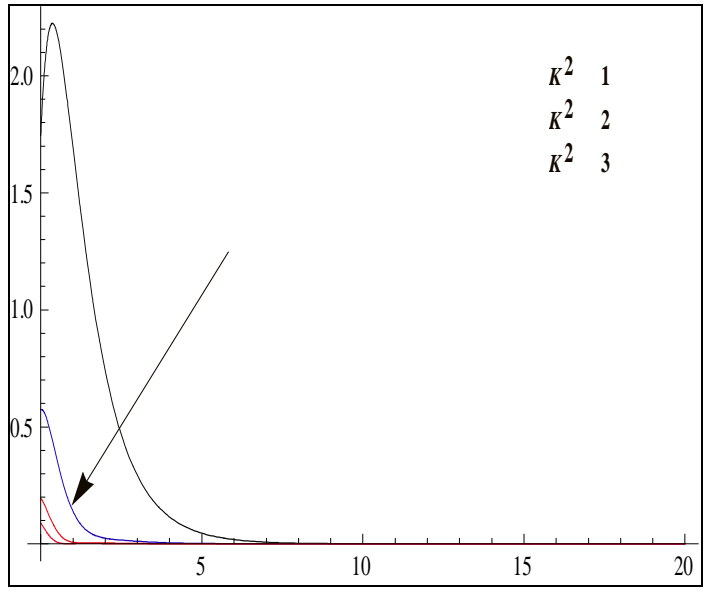

Figure 10: Main Velocity for various values of $\mathrm{K}^{2}$

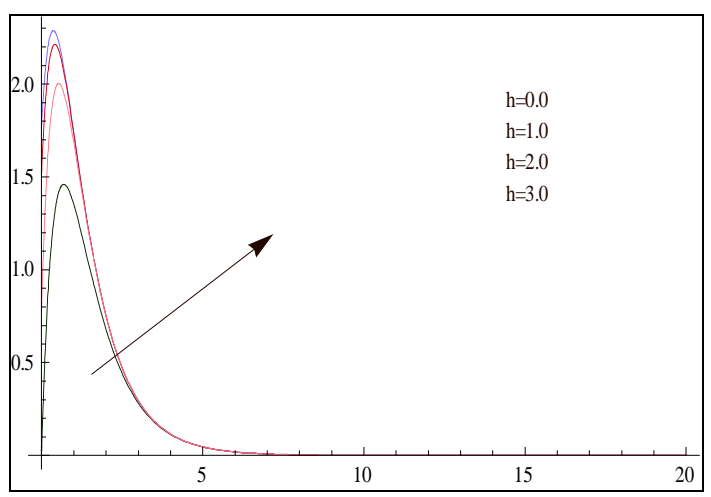

Figure 12: Main Velocity for various values of $h$ 




Figure 13: Main Velocity for various values of $M$

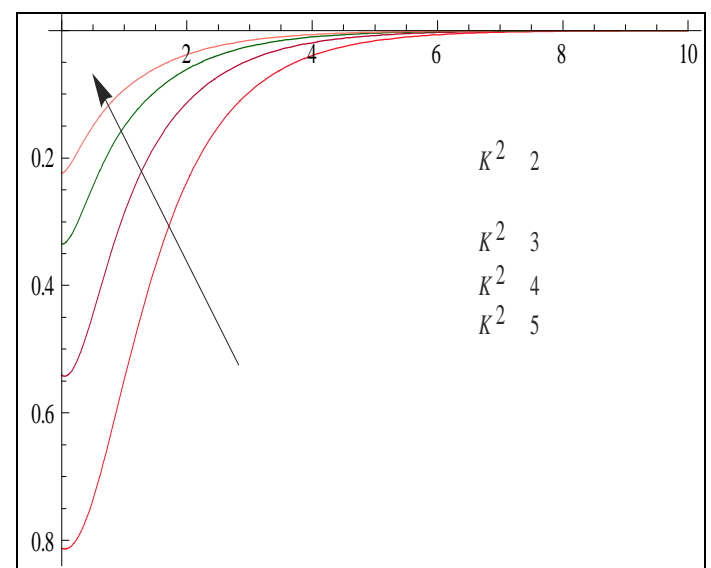

Figure 15: Cross Velocity for various values of Rotation Parameter $\mathrm{K}^{2}$



Figure 17: Cross Velocity for various values of Rotation values of Soret Effects $\mathrm{S}_{0}$

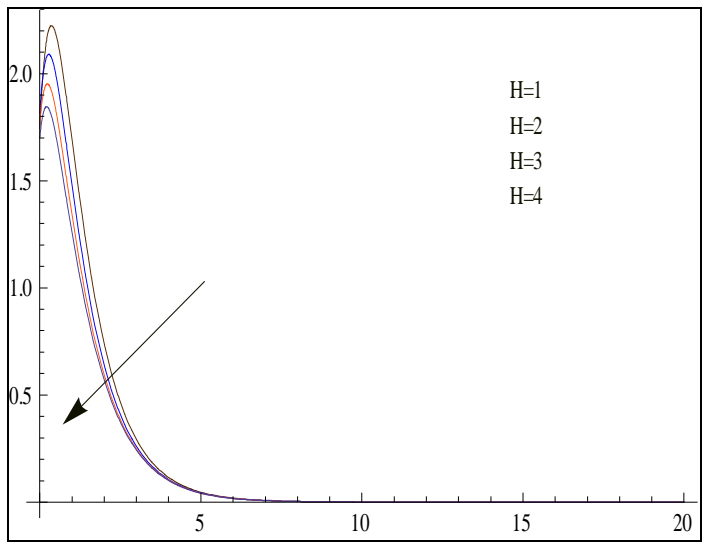

Figure 14: Main Velocity for various values of $H$

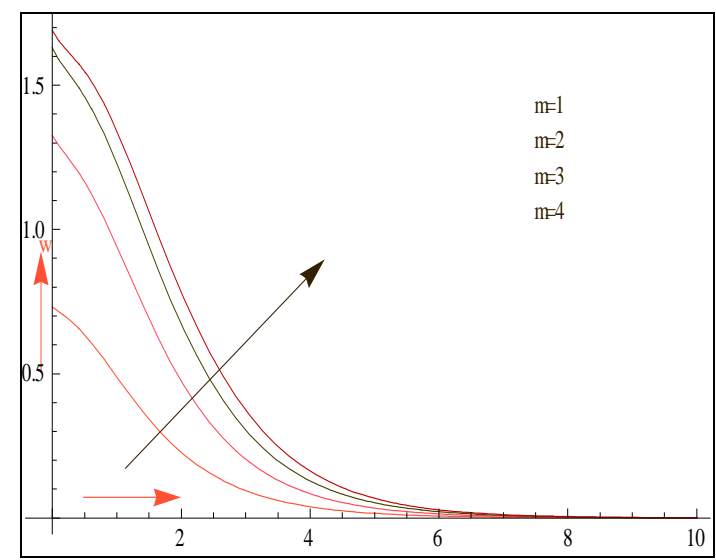

Figure 16: Cross Velocity for various Parameter m

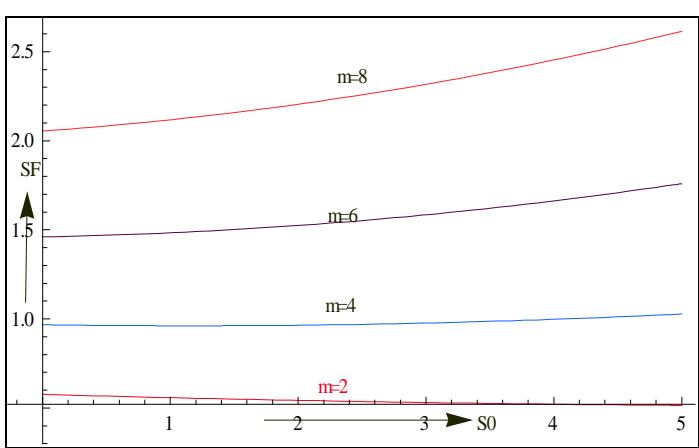

Figure 18: Skin Friction for various values of Hall Parameters m 


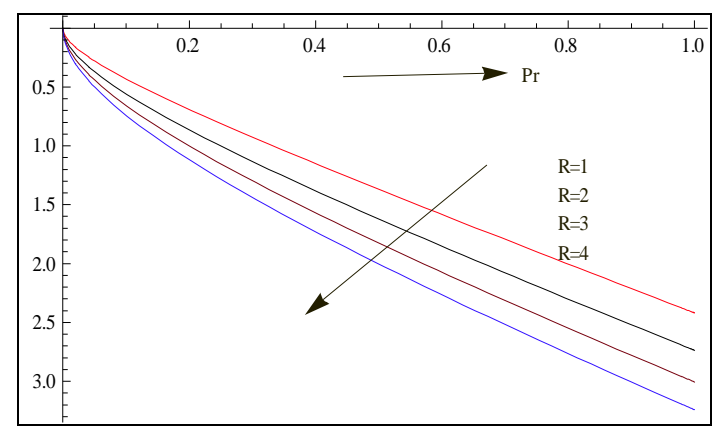

Figure 19: Heat flux for various values of Radiation Parameter R

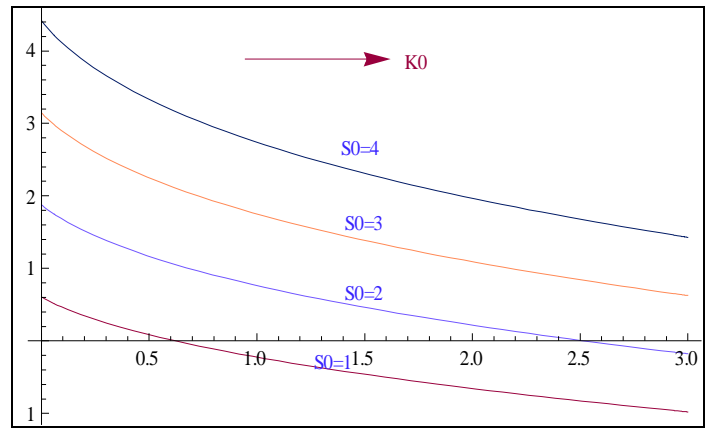

Figure 20: Mass flux for various values of Soret Effect $S_{0}$

\section{CONCLUSION}

In this work, we have studied the Hall effects on magnetohydrodynamics slip flow past a porous vertical plate with radiation and Soret effect in rotating system. The governing equations are solved by using perturbation techniques. An asymptotic solution of the resulting differential equations under the prescribed boundary conditions is obtained. Numerical results are discussed with help of graphs. The conclusions of the study are as follows:

Both primary and secondary velocities increase while increase of Grashof numbers. Increase of Soret effect enhances the velocity of the fluid flow. Increase of Hall parameter decreases the primary velocity but the reverse process exists for the secondary velocity. Increase of slip flow parameter enhances both the primary and secondary velocities. Rotation parameter retards the primary velocity of the fluid flow. But the reverses processes exists in cross section velocity of the fluid flow. Increase of Soret number enhances the primary and secondary velocities. Increase of Magnetic parameter retards both the primary and secondary velocity of the fluid flow. Temperature profile shows decrease effects while increase of both radiation and Prandtl number, but the reverse process exists if increase of Soret effect in the concentration field. Here, consider the skin friction as function of hall parameter enhances the skin friction profile.

\section{APPENDIX}

$$
\begin{aligned}
& m_{1}=\frac{-\operatorname{Pr}(1+H)-\sqrt{\operatorname{Pr}^{2}(1+H)^{2}+4 \operatorname{Pr} R}}{2}, m_{2}=\frac{-\operatorname{Pr}(1+H)-\sqrt{\operatorname{Pr}^{2}(1+H)^{2}+4 \operatorname{Pr}\left(R-\frac{n}{4}\right)}}{2} \\
& m_{3}=\frac{-S c-\sqrt{S c^{2}+4 S c K_{0}}}{2} \\
& m_{4}=\frac{-S c-\sqrt{S c^{2}-4\left(\frac{S c n}{4}-S c K_{0}\right)}}{2}
\end{aligned}
$$




$$
\begin{aligned}
& m_{5}=\frac{-1-\sqrt{1+4\left(M_{1}+2 i K^{2} \frac{1}{K_{0}}\right)}}{2}, \quad m_{6}=\frac{-1-\sqrt{1+4\left(M_{1}+2 i K^{2} \frac{1}{K_{0}}-\frac{n}{4}\right)}}{2} \\
& A_{5}=\frac{\left(-\operatorname{Pr} m_{1}\right)}{m_{2}^{2}+\operatorname{Pr} m_{2}+\operatorname{Pr}(H-R+n / 4)}, A_{4}=1-A_{5} ; \\
& A_{8}=\frac{\left(-S c S r m_{1}^{2}\right)}{m_{2}^{2}+S c m_{2}-S c K_{0}}, A_{7}=1-A_{8} ; \\
& A_{17}=1-\left(A_{18}+A_{19}+A_{20}+A_{21}\right), A_{18}=\frac{\left(-S c m_{3} A_{7}\right)}{m_{3}^{2}+S c m_{3}+\left(\frac{S c n}{4}-S c K_{0}\right)} \\
& A_{19}=\frac{\left(-S c m_{1} A_{8}\right)}{m_{1}^{2}+S c m_{1}+\frac{S c n}{4}-S c K_{0}}, A_{20}=\frac{\left(-S c S r m_{2}^{2} A_{4}\right)}{m_{2}^{2}+S c m_{2}+\frac{S c n}{4}-S c K_{0}}
\end{aligned}
$$$$
A_{21}=\frac{-S c S r m_{1}^{2} A_{5}}{m_{2}^{2}+S c m_{2}+\frac{S c n}{4}-S c K_{0}}, A_{32}=\frac{-G m A_{19}}{m_{1}^{2}+m_{1}-\left(M_{1}+2 i K^{2}+\frac{1}{K_{0}-\frac{n}{4}}\right)},
$$

$$
A_{24}=\frac{-m_{5} A_{10}}{m_{5}^{2}+m_{5}-\left(M_{1}+2 i K^{2}+\frac{1}{K_{0}-\frac{n}{4}}\right)}, A_{25}=\frac{-m_{1} A_{11}}{m_{1}^{2}+m_{1}-\left(M_{1}+2 i K^{2}+\frac{1}{K_{0}-\frac{n}{4}}\right)}
$$

$$
A_{26}=\frac{-m_{3} A_{12}}{m_{3}^{2}+m_{3}-\left(M_{1}+2 i K^{2}+\frac{1}{K_{0}-\frac{n}{4}}\right)}, A_{27}=\frac{-m_{1} A_{13}}{m_{5}^{2}+m_{5}-\left(M_{1}+2 i K^{2}+\frac{1}{K_{0}-\frac{n}{4}}\right)}
$$

$$
A_{28}=\frac{-G r A_{4}}{m_{2}^{2}+m_{2}-\left(M_{1}+2 i K^{2}+\frac{1}{K_{0}-\frac{n}{4}}\right)}, A_{29}=\frac{-G r A_{5}}{m_{1}^{2}+m_{1}-\left(M_{1}+2 i K^{2}+\frac{1}{K_{0}-\frac{n}{4}}\right)}
$$

$$
A_{30}=\frac{-G m A_{17}}{m_{4}^{2}+m_{4}-\left(M_{1}+2 i K^{2}+\frac{1}{K_{0}-\frac{n}{4}}\right)}, A_{31}=\frac{-G m A_{18}}{m_{3}^{2}+m_{3}-\left(M_{1}+2 i K^{2}+\frac{1}{K_{0}-\frac{n}{4}}\right)}
$$




$$
\begin{aligned}
A_{33}= & \frac{-G m A_{20}}{m_{2}^{2}+m_{2}-\left(M_{1}+2 i K^{2}+\frac{1}{K_{0}-\frac{n}{4}}\right)}, A_{34}=\frac{-G m A_{21}}{m_{1}^{2}+m_{1}-\left(M_{1}+2 i K^{2}+\frac{1}{K_{0}-\frac{n}{4}}\right)} \\
A_{23}= & -\left(\begin{array}{ll}
A_{24}\left(1-h m_{4}\right)+A_{25}\left(1-h m_{1}\right)+A_{26}\left(1-h m_{6}\right) \\
+A_{27}\left(1-h m_{1}\right)+A_{28}\left(1-h m_{2}\right)+A_{29}\left(1-h m_{1}\right) \\
+A_{30}\left(1-h m_{4}\right)+A_{31}\left(1-h m_{3}\right)+A_{32}\left(1-h m_{1}\right) \\
+A_{33} & \left(1-h m_{4}\right)+A_{34}\left(1-h m_{1}\right)
\end{array}\right)
\end{aligned}
$$

\section{REFERENCES}

1. H.L. Agarwal, P.C. Ram and V. Singh, Effects of Hall Currents on the hydro-magnetic free convection with mass transfer in a rotating fluid". Astrophys Space Science, 1984, 100,279-283.

2. Akindele Michael Okedoye, Analytical solution of MHD free convective heat and mass Transfer flow in a porous medium".The Pacific Journal of Science and Technology, 2013,14,2, 225-245

3. K. Balamurugan, S. Anuradha and R. Karthikeyan, Chemical reaction effects on Heat and Mass Transfer of Unsteady flow over an infinite vertical porous plate embedded in a porous medium with heat source". International Journal of Scientific and Engineering Research, 2014,5, ,1179-1193

4. K.S. Balamurugan, S.V.K. Varma, K. Ramakrishanaprasad, Thermo diffusion and chemicalreaction effects on a three dimensional MHD Mixed convective flow along an infinite vertical porous plate with viscous and Joules dissipation. International Journal of Advances in Science and Technology.2001.3, 73-92.

5. Jaiswal B.S and Soundalgekar V.M., Oscillating plate temperature effects on a flow past an infinite porous plate with constant suction and embedded in a porous medium. Heat and Energy.1986,10,97-100

6. B.S. Jha, R. Prasad and S. Rai, Mass Transfer effects on the flow past an exponentially Accelerated vertical plate with constant heat flux. Astrophysics and space science, 1991,181, 125-134.

7. Y.J. Kim, Unsteady MHD Convective heat transfer past a semi-infinite vertical porous Moving plate with variable suction. International Journal of EngineeringScience.2000, 38,833-845.

8. H.Kumar, Radiative heat transfer with hydro magnetic flow and viscous dissipation over stretching surface in the presence of variable heat flux. Thermal Science, 2009, 13, 163-169. 
9. M.J. Lighthill, The response of laminar skin friction and heat transfer to fluctuation in the in the stream velocity.Proc.R.Soc.A, 1954,224, 1-23.

10. O.D. Makinde, J.M. Mango, D.M. Theuri. Unsteady free convection flow with suction on an Accelerating porous plate.AMSE.J.Mod.Meas.2003, 72, 39-46.

11. E. Maygari, I.Pop and B. Keller. "Analytical solutions for Unsteady free convection flow through a Porous media". Journal of Engineering Math.2004,48,93-104

12. U. Mbeledogu and A.Ogulu. Heat and mass transfer of an unsteady MHD natural convection flow of a rotating fluid past a vertical porous flat plate in the presence of radiative heat transfer. International Journal of Heat and Mass Transfer.2007, 1902-1908.13.

13. R. Muthucumarasamy, Effect of Heat and mass transfer on flow past an oscillatory vertical plate with variable temperature. International Journal of Appl.Math and Mech, 2008, 4, 5965.

14. A.A. Raptis, Flow through a porous medium in the presence of magnetic field. International Journal of International Journal of Energy.1986, 10, 97-100.

15. A.A. Raptis, N. Kafousias, "Heat Transfer in flow through a porous medium bounded by an infinite vertical plate under the action of a magnetic field". Int.J.Energy .1982, 6,241-245.

16. K. Sarada and B. Shanker, 2013, "The Effects of Soret and Dufour on an unsteady MHD free Convection flow past a vertical porous plate in the presence of suction or injection". International Journal of Engineering and Science, 2013, 2, 7, 35-46.

17. K.D. Singh and R. Kumar, 2009, "Combine effects of hall current and rotation on free convection MHD flow in a porous channel". Indian Journal of Pure and Applied Physics,2009, 47,617-623

18. G. Srinivasa Rao et.al. Soret and Dufour effects on MHD Boundary layer flow over amoving vertical porous plate with suction".International Journal of Emerging Trends in Engineering and Development, 2014,4, 2, 63-72

\section{Corresponding author: V.Gopikrishnan}

Assistant Professor, Department of Mathematics, Shanmuga Industries

Arts and Science College, Tiruvannamalai,Tamilnadu, India.

On line publication Date: 30.08.2017 